\title{
Healthcare providers' utilization and perception on telemedicine: urgency amidst COVID-19 pandemic
}

\author{
Silvalena ${ }^{1}$, Rizma Adlia Syakurah ${ }^{2}$ \\ ${ }^{1}$ Medical Profession Program, Faculty of Medicine, Sriwijaya University, Palembang, Indonesia \\ ${ }^{2}$ Department of Public Health, Faculty of Public Health, Sriwijaya University, Palembang, Indonesia
}

\begin{tabular}{l}
\hline Article Info \\
\hline Article history: \\
Received Apr 8, 2021 \\
Revised Nov 23, 2021 \\
Accepted Dec 2, 2021 \\
\hline
\end{tabular}

Keywords:

COVID-19

Healthcare provider

Pandemic

Telemedicine

Utilization

\begin{abstract}
The outbreak of coronavirus disease 2019 (COVID-19) in Indonesia had awakened the fact that the country's healthcare system could not stand-alone with conventional in-person healthcare service. The sudden massive adaptation of telemedicine in Indonesia still needed be reassess periodically, especially with blooming numbers of users. This cross-sectional study conducted on medical doctors, dentists, and specialist in Indonesia, aimed to evaluate the utilization and perception of healthcare providers towards telemedicine in Indonesia during COVID-19 pandemic. Data were collected using convenience sampling from an online questionnaire through social media from June 16-29, 2020. Data were analyzed using Chi-square test $(\mathrm{p}$-value $<0.05)$ and prevalence ratios $(\mathrm{PR})$ with $95 \%$ confidence interval (CI). Most physicians who practiced using telemedicine admitted that they used telemedicine as an alternative during pandemic (71.2\%). The usage of telemedicine had an association with the idea that telemedicine provided the patients' needs $(\mathrm{p}<0.001,95 \% \mathrm{CI}=3.53(1.86-6.70)$ and provided knowledge for the society $(\mathrm{p}=.04795 \% \mathrm{CI}=3.54(0.93-13.51))$. The potential and benefits of telemedicine could be recognized during the pandemic, though the use of collaborative media and the advancement of platform features for a better quality of diagnosis could be improved The policymakers and stakeholders expected to establish a balanced and thoughtful framework of telemedicine.
\end{abstract}

This is an open access article under the CC BY-SA license.

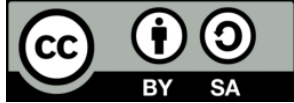

\section{Corresponding Author:}

Rizma Adlia Syakurah

Public Health Faculty, Sriwijaya University

Jl. Raya Palembang-Prabumulih KM. 32 Indralaya, Ogan Ilir, Sumatera Selatan, 30662, Indonesia

Email: rizma.syakurah@gmail.com

\section{INTRODUCTION}

The pandemic of coronavirus disease 2019 (COVID-19) has started at the end of 2019 and is still being a huge concern to many sectors especially medical sectors. In Indonesia, the first COVID-19 case was reported on March 2, 2020, subsequently reaching 457,735 positive cases, 385,094 cases of recovery and 15,037 cases of death by November 13, 2020 [1]. Public health services such as hospitals and clinics as well as private practice were overwhelmed with the surge in demands for medical health services [2]. Public health services was quite a quandary for the worldwide healthcare system to keep up the capacity to provide services not only for patients who suffer from COVID-19, but also people who needs care for acute or chronic diseases as well as trauma patients while protecting both healthcare providers and patients [3]. COVID-19 has a highly infectious and progressive behavior that causes all countries to take immediate action to stop the increasing mortality rate of COVID-19 [4]. Indonesia took a very wise decision in order to minimize the dissemination of this deathly virus. Implementation of telemedicine-based health service was 
then adapted, later inaugurated into the regulation of Ministry of Health Number HK 02.01. The legislations includes recommendation of telemedicine usage for health services in order to prevent the spread of COVID-19 [5], [6].

Adapting such a high-functioning program takes time and cannot happen in a short period of time. The adaptations required precise guidelines, human and facility resources, funding as well as reviewing the trials and errors throughout the process [3]. Looking at the guidelines Indonesia had made and the running standalone telemedicine as well as hospital-linked telemedicine, there were some regulations that unimplemented on the existing telemedicine. Compared to other countries who have implemented telemedicine such as Singapore and India, Indonesia's telemedicine regulations was not clear [7]. For example, the telemedicine regulations of Singapore and India certainly stated the requirements for healthcare providers to register and the training they would have. These regulations also classify types of drugs allowed and restricted for telemedicine practices. Besides, this regulation also functions as a protection for the rights and obligations of doctors and patients so that if there is a violation of rules to any party, a fair legal manner should be followed. Thus, these regulations would aid to cut down number of medical malpractices in a country [8]-[10]

In this era of COVID-19 pandemic, people are advised to stay at home and consult through telemedicine for complaints as much as possible to avoid visiting the hospitals if there is no urgency, so it can be reducing exposure [5], [11]. Recently, there has been a breakout of telemedicine platform in Indonesia of more than 20 platforms. Although telemedicine platforms in Indonesia appear to be very well designed, there are still doubts especially on the safety and confidentiality of patients' and doctors' data stored on telemedicine platform. Therefore, evaluation of the use of telemedicine according to health care providers (doctors) and patients' point of view is needed. This research aims to evaluate the perception of telemedicine among healthcare providers in Indonesia.

\section{METHOD}

This research was an observational analytic study with a cross-sectional approach conducted on medical doctors, dentists, and specialist in Indonesia. The sampling technique was done by convenience sampling. Data obtained from June 16-29, 2020 using online-questionnaires through social media platforms such as Line, WhatsApp, Instagram and Twitter.

The instrument covered healthcare providers' characteristics (four items), personal perception (five items) and utilization (five items) on telemedicine and took approximately 10-15 minutes to complete. The questionnaire contains questions used to obtain related data or information personal perception and utilization of telemedicine by healthcare providers, such as whether telemedicine provides the needs of people, helps increase the knowledge of the society, is able to replace conventional in-person healthcare service, can be used as a tool to further develop healthcare services and can help to work up patients' adherence. The instrument personal perception using of closed-ended questions consist of "yes" or "no" options, while the personal utilization using open-ended questions. The instrument was accessible through a link and was distributed to different geographic regions. This study was also observations on telemedicine platforms in Indonesia to compare and assess the availability of telemedicine in Indonesia as well as services provided by each platform.

Data obtained were coded, validated, and analyzed using IBM SPSS Statistic 24. Univariate analysis was used to describe the healthcare provider's characteristics and perception utilization on telemedicine as frequency distribution and in tabulated form. Bivariate analysis used to find the proportions and level of association between users and non-users of telemedicine platform to the opinions of telemedicine with Chisquare test as significance at $\mathrm{p}<0.05$ and prevalence ratios (PR) with $95 \% \mathrm{CI}$.

This research was approved by Mohammad Hoesin Central General Hospital and Faculty of Medicine Sriwijaya University Health Research Review Committee (IRB No.82/kepkrsmhfkunsri/2020). All participants were informed of the study and provided consent before enrolling. Attribute codes were given to the participants to maintain anonymity.

\section{RESULTS AND DISCUSSION}

This study evaluated the utilization and perception of healthcare providers towards telemedicine in Indonesia during COVID-19 pandemic. The result provided the first nationwide of perceptions of healthcare providers towards telemedicine in Indonesia during pandemic. Several telemedicine platforms in Indonesia with the most users are Mobile JKN, Sehat Pedia, Halodoc, Alodokter. Three of four platforms provide consultation via built-in text messages between doctors and patients, only Halodoc provides consult via teks, telephone, and video call. However, Halodoc and Alodokter platform has paid consultation while the others

Int J Public Health Sci, Vol. 11, No. 1, March 2022: 287-293 
are free for consulting medical doctors. Comparing the four platforms, all platforms except Alodokter, partnered with hospitals and clinics, some also has partnership with pharmacies, national insurance (BPJS) and private insurance. Though all of the platforms provides health-related articles, only SehatPedia has had a feature known as "e-policy" containing Laws and official letters from Ministry of Health. Furthermore, Halodoc is the only platform that provides prescription of drugs or accepts drug purchases with uploads of conventional prescription. Apart from that, each telemedicine platform may have their own unique features. The comparisons of telemedicine platform are presented in Table 1.

Table 1. Comparison of telemedicine platforms in Indonesia

\begin{tabular}{|c|c|c|c|c|}
\hline \multirow{2}{*}{ Variables } & \multicolumn{4}{|c|}{ Telemedicine platforms } \\
\hline & Mobile JKN & SehatPedia & Halodoc & Alodokter \\
\hline Developer & $\begin{array}{l}\text { Government-based (17 April } \\
\text { 2016) }\end{array}$ & $\begin{array}{l}\text { Government-based (20 } \\
\text { September 2018) }\end{array}$ & $\begin{array}{l}\text { Private-based } \\
\text { (11 March 2016) }\end{array}$ & $\begin{array}{c}\text { Private-based } \\
\text { (13 March } \\
\text { 2016) }\end{array}$ \\
\hline Review/Rating & $3.8 / 5$ & $4.2 / 5$ & $4.8 / 5$ & $4.6 / 5$ \\
\hline downloads & $>10,000,000$ & $>10,000$ & $\begin{array}{l}>1,000,000 \\
\text {-Watson }\end{array}$ & $>5,000,000$ \\
\hline Partner(s) & BPJS & BPJS & $\begin{array}{l}\text { Pharmacy } \\
\text {-Private } \\
\text { Insurance } \\
\text {-Prodia } \\
\text { Laboratory }\end{array}$ & $\begin{array}{l}\text { Century } \\
\text { pharmacy }\end{array}$ \\
\hline Link with hospitals/clinics & Yes & Yes & $\begin{array}{l}\text { Yes } \\
\text { Text }\end{array}$ & No \\
\hline Media & Text & Text & $\begin{array}{c}\text { Phone } \\
\text { Video call }\end{array}$ & Text \\
\hline $\begin{array}{l}\text { Consult with medical } \\
\text { doctors }\end{array}$ & Free of charge & Free of charge & Paid & Paid \\
\hline $\begin{array}{c}\text { Consult with } \\
\text { specialist/subspecialist }\end{array}$ & Paid & Free of charge & Paid & Paid \\
\hline Prescription & - & - & Yes & - \\
\hline
\end{tabular}

A total of 434 respondents were participated to fill the online questionnaires, eligible, consented, and completed the survey. Out of 434 respondents, about two-third of them were female doctors $(66.1 \%)$, and respondents ages ranged from 22 years old to 80 years old, with a mean age of 33.46 (SD \pm 10.009$)$ years old. The majority of respondents were medical doctors $(68.4 \%)$, followed by specialist $(20.7 \%)$, dentist $(8.3 \%)$, and others $(2.5 \%)$. Respondents claim to have in-person practice $(80.9 \%)$ while only $27.2 \%$ respondents were users of telemedicine platforms as shown in Table 2.

Table 2. Demography of respondents $(\mathrm{n}=434)$

\begin{tabular}{clc}
\hline No. & Variable & $\mathrm{n}(\%)$ \\
\hline 1. & Age & $31(22-80)$ \\
2. & Gender & \\
& Male & $147(33.9)$ \\
& Female & $287(66.1)$ \\
3. & Professions & \\
& Medical doctor & $297(68.4)$ \\
& Dentist & $36(8.3)$ \\
& Specialist & $90(20.7)$ \\
& Others & $11(2.5)$ \\
4. & Practices in-person health service \\
& Yes & $351(80.9)$ \\
& No & $83(19.1)$ \\
5. & Practice using telemedicine & \\
& Yes & $118(27.2)$ \\
& No & $316(72.8)$ \\
\hline
\end{tabular}

In the Table 3, type of profession has significant relation with using telemedicine $(\mathrm{p}=.001)$. Over $90 \%$ of respondents who use telemedicine agreed that telemedicine provides what patient need $(\mathrm{p}=0.000)$ and telemedicinecan help to increase the knowledge of the society $(\mathrm{p}=0.047)$. More than $90 \%$ of the non-users agreed that telemedicine platforms could help to increase the knowledge of the society and that telemedicine could be used as a tool to further develop healthcare services. However, only a little portion of the users (18.6\%) agreed that telemedicine platforms would be able to replace conventional in-person health service that telemedicine and only half of the users agreed that telemedicine could help to work up patients' adherence. 
Table 3. Personal perception on telemedicine

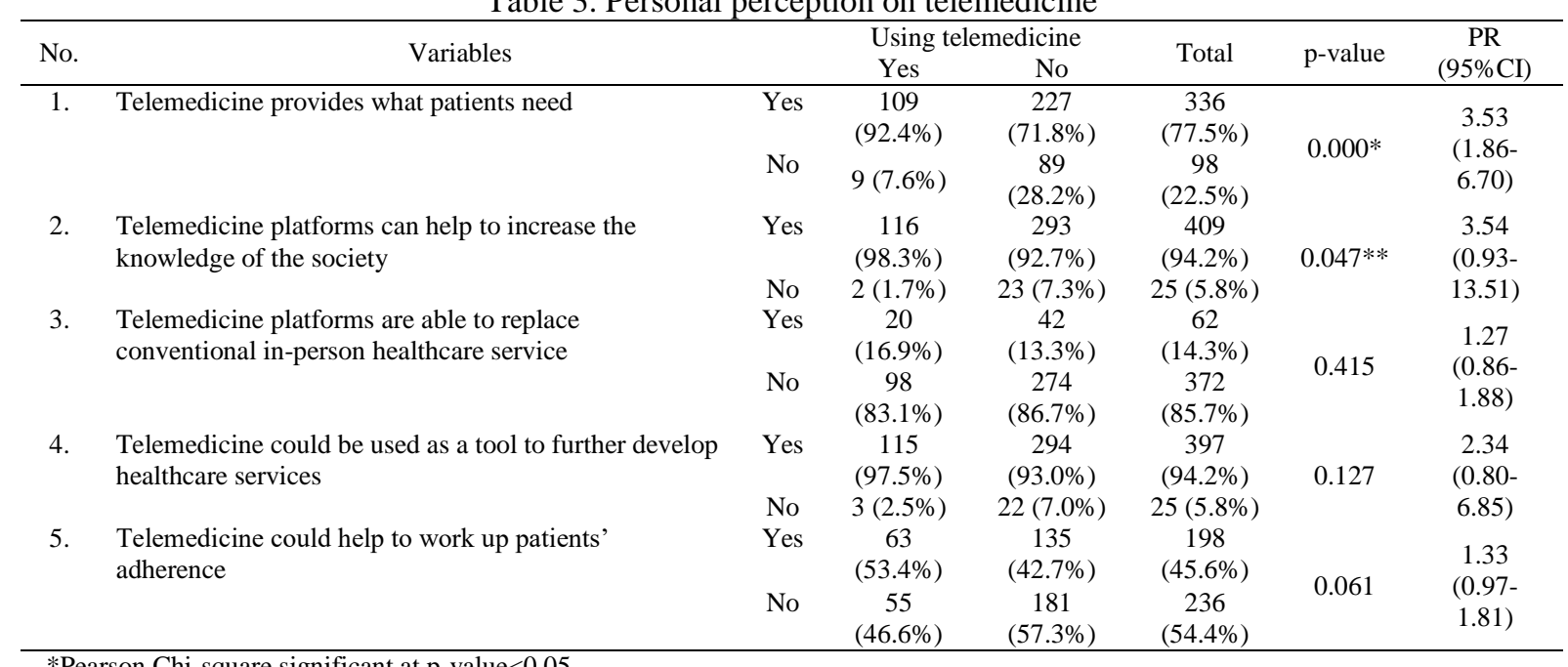

*Pearson Chi-square significant at p-value $<0.05$

$* *$ Continuity Correction significant at p-value $<0.05$

Out of 434 respondents, 118 respondents were telemedicine platforms users as shown in Table 4. Almost $70 \%$ of them used private company-based telemedicine while only $16.9 \%$ of them used hospitallinked telemedicine. Most respondents used telemedicine for daily practice because of its flexible working time $(75.4 \%)$ and telemedicine is also an alternative during the pandemic $(71.2 \%)$. More than half of the respondents agreed that the disadvantage of using telemedicine is unable to do physical examination and the setbacks of using telemedicine is unstable network connection $(40.7 \%)$. Around $20 \%$ of the users believe advancement of features in the telemedicine platforms can improve quality of telemedicine service.

Table 4. Utilization of telemedicine $(n=118)$

\begin{tabular}{clc}
\hline No. & \multicolumn{1}{c}{ Variables } & $\mathrm{n}(\%)$ \\
\hline 1. & Telemedicine platform used & \\
& Government-based & $16(13.6)$ \\
& Private company-based & $82(69.5)$ \\
Hospital-linked & $20(16.9)$ \\
2. & Perceptions on advantages of telemedicine & \\
& Flexible working time & $89(75.4)$ \\
Alternative during pandemic & $84(71.2)$ \\
Education for community & $76(64.4)$ \\
Practical and easy access & $28(23.7)$ \\
Minimizing contact with patients & $17(14.4)$ \\
Effective part-time job & $55(46.6)$ \\
Easy to use application & $44(37.3)$ \\
Triage to sort emergency patients to hospitals & $10(8.5)$ \\
Provides drug prescription & $6(5.1)$ \\
Others & $5(4.2)$ \\
Perception on disadvantage of telemedicine & \\
Unable to do physical examination & $63(53.4)$ \\
Difficult to make diagnosis & $21(17.8)$ \\
Difficult to maintain good doctor-patient communication & $13(11.0)$ \\
Regulation is not clear & $8(6.8)$ \\
Others & $13(11.0)$ \\
Problem during utilization of telemedicine & \\
Unstable network connection & $48(40.7)$ \\
Language and communication process & $19(16.1)$ \\
No appropriate medical data & $19(16.1)$ \\
Uncooperative patients & $10(8.5)$ \\
Others & $22(18.6)$ \\
Areas that can be improved & \\
Advancement of features needed to improve diagnosis & $26(22.0)$ \\
Network connection stability & $14(11.9)$ \\
Collaborations with hospitals/clinics/pharmacy/laboratory & $11(9.3)$ \\
Others & $9(7.6)$ \\
& & $19(16.1)$ \\
\hline
\end{tabular}

Int J Public Health Sci, Vol. 11, No. 1, March 2022: 287-293 


\subsection{Demography and healthcare providers' perception on telemedicine}

This study focused on healthcare providers' perception and utilization of telemedicine during the COVID-19 pandemic. Telemedicine has been a great invention that aid medical sectors to doctors at all generations. Young adults (18-35 years old) use technologies wider and deeper that the older adults (above 65 years old) [12], [13]. This finding is in line with present study that healthcare providers' mean age of 33 years has response on this study. However, there is no difference of age with using telemedicine in this study. Nowadays, the utilization of technology used to the fullest by generation. Over the last decade, health information has been a part of the spotlight among internet user and the number of search related to healthcare is continued growing [14]. This supports our finding that there were an associated between the usage of telemedicine and the idea that telemedicine can increase knowledge of the society.

Digitalization of medical world has been introduced to medical students through their education earlier than other medical type professions such as specialist and dentist. As a result, most medical doctors are common to telemedicine and its development. Medical doctors could make use of this knowledge to fulfill their role in the society in order to meet the healthcare demands [15], [16]. Majority of physicians opine telemedicine was an alternative medical practice during the COVID-19 pandemic as to minimize contact with patients and as a triage to sort emergency patients. This finding is also in line with the data findings that recently, the majority of physicians started using the telemedicine since the COVID-19 pandemic (<6 months).

Although the existing telemedicine platform originates from private company base, some telemedicine also originates directly from hospitals or provides services that connect telemedicine devices directly to the physician's workplace (hospital-linked telemedicine), indicating that telemedicine was present as part of the "forward triage" of hospitals in controlling the surge in health care demand during the COVID-19 pandemic [17]. Through telemedicine, hospitals could sorted out patients present in the emergency department, which allowed protection of patients, physicians and the community from increased the risk of exposure to COVID-19 while simultaneously provided any health care aid needed such as consultation and drug prescription and not cause a flood of patients [18], [19].

\subsection{Perception utilization on telemedicine}

The number of patients' visits in telemedicine platforms dramatically increased within the days of pandemic where in-person healthcare service access is restricted for good. The needs to consult and relieve the worries of having 'probable' health problems, the necessity to have drugs prescribed for chronic diseases, and expecting of health information or education are usually the interest of patients when they seek for healthcare services. Telemedicine was a great invention that provides and cover all these interest in one go. Telemedicine brings along very wide-open employment opportunities for healthcare providers during the COVID-19 pandemic, that also beneficial for patients in telemedicine platforms that they did not need to queue for long to address their complaints because there are plenty of physicians available [20]. Telemedicine counselling program also could keep patients from unrequired medical service utilization and might spare patients [21]. Moreover, the pandemic had contributed to causing some countries waiving and relaxed their regulation to allow telemedicine to have drug prescription [22], [23]. Therefore, this strengthens the findings there was a significant association between the idea that telemedicine provides the needs of patients and the usage of telemedicine among healthcare providers.

Although various advantages of the telemedicine use strategy have been made available, various barriers are still present in the overall implementation of telemedicine [24] [25]. The various platforms available are platforms that were present before the COVID-19 pandemic existed, thereby reducing the limitations of telemedicine in connection with funding issues in telemedicine development. However, the problem that still constrains the use of telemedicine in clinical practice is the reluctance of doctors to adapt telemedicine [17], [26]. This is presumed that the lack of health professionals' knowledge and awareness of the new technologies and the skills to use them [27], [28]. This finding is consistent with the findings of the data showing only a quarter of the total number of physicians who use telemedicine as part of medical practice. Also, some setbacks mentioned by physicians are language and communication problems with patients, especially uncooperative patients in telemedicine [15]. In fact, telemedicine response during COVID-19 requires the skills of physicians in changing delivery methods and clinical practice as needed. Some cases or consultations required a physical check and supportive examinations, that would be difficult to do through telemedicine, so physicians must be able to use alternative methods to obtain information in this situation and this could be obtained by previous training [17]. However, physicians claim that there are some physical examinations that are impossible to be done through telemedicine and thus might affect the quality of diagnosis. This was a reason why the telemedicine insignificant to replace completely the conventional healthcare service.

Providing permanent telemedicine from time to time would help establish a sustainable service model which useful when facing a health emergency, such as the COVID-19 pandemic [17], [29]. For this 
reason, a form of training and accreditation are needed for physicians who meet the standards to carry out telemedicine programs. This could also be a suggestion to the government in adapting the criteria for implementing telemedicine from other countries by making the provision of "training" a prerequisite for telemedicine practices for both the platform and the physician who runs telemedicine [8], [9]. Many telemedicine user physicians suggested enhancement in quality of telemedicine application in terms of feature such as enabling photo sending or video consult and continuity of application as it runs. Additionally, collaborations with pharmacy in order to accommodate drug prescription feature could be a plus point. These factors could highly affect the improvement in quality of telemedicine service [30]. Telemedicine has tremendous potential and as the pandemic goes on, telemedicine will be a great complementary to healthcare system.

\section{CONCLUSION}

The COVID-19 pandemic brought telemedicine into a new light. Telemedicine is here to stay and it's simply matter of adapting to medical practices. We believe that telemedicine can potentially be beneficial and important part of future healthcare services. However, telemedicine is also important, especially for policy makers and stakeholders, to balance the benefits of telemedicine against the risks for the patients' safety. By establishing a balanced and thoughtful framework in using telemedicine platforms, patients, healthcare provider as well as the system itself will finally notice the potential of telemedicine as a future healthcare services and a great complementary to healthcare system.

\section{REFERENCES}

[1] Committee for Handling COVID-19 and National Economic Recovery, “COVID-19 distribution Map," 2020. https://covid19.go.id/peta-sebaran-covid19 (accessed Nov. 18, 2020).

[2] B. Moazzami, N. Razavi-Khorasani, A. Dooghaie Moghadam, E. Farokhi, and N. Rezaei, "COVID-19 and telemedicine: Immediate action required for maintaining healthcare providers well-being," Journal of Clinical Virology, vol. 126, p. 104345, May 2020, doi: 10.1016/j.jcv.2020.104345.

[3] R. Bashshur, C. R. Doarn, J. M. Frenk, J. C. Kvedar, and J. O. Woolliscroft, "Telemedicine and the COVID-19 pandemic, lessons for the future," Telemedicine and e-Health, vol. 26, no. 5, pp. 571-573, May 2020, doi: 10.1089/tmj.2020.29040.rb.

[4] K. Yuki, M. Fujiogi, and S. Koutsogiannaki, "COVID-19 pathophysiology: A review," Clinical immunology, vol. 215, p. 108427., 2020.

[5] Ministry of Health Republic Indonesia, "Circular Letter Number HK.02.01/MENKES/303/2020 of 2020 concerning the implementation of health services through the use of communication information technology in the context of preventing the spread of COVID-19. Indonesia,” $2020 . \quad \mathrm{https} / /$ covid19.hukumonline.com/wpcontent/uploads/2020/07/surat_edaran_menteri_kesehatan_nomor_hk_02_01_menkes_303_2020_tahun_2020.pdf (accessed Nov. $18,2020)$.

[6] R. Ohannessian, T. A. Duong, and A. Odone, "Global telemedicine implementation and integration within health systems to fight the COVID-19 pandemic: a call to action," JMIR Public Health and Surveillance, vol. 6, no. 2, p. e18810, Apr. 2020, doi: $10.2196 / 18810$.

[7] N. K. Putri and A. Sujiwa, "Health students' perspectives on the feasibility of telemedicine implementation in Indonesia," European Journal of Molecular \& Clinical Medicine, vol. 7, no. 5, pp. 746-751, 2020.

[8] Ministry of Health Singapore, "National telemedicine guidelines," 2015. https://www.moh.gov.sg/resourcesstatistics/guidelines/national-telemedicine-guidelines (accessed Nov. 18, 2020).

[9] S. Patil et al., The interface between law and technology. Navrachana University in Association with Gujarat National Law University, 2021.

[10] Ministry of Health Republic Indonesia, "Regulation of the Minister of Health Number 20 of 2019 concerning the implementation of telemedicine services between health care facilities," 2019. https://peraturan.bpk.go.id/Home/Details/138613/permenkes-no20-tahun-2019 (accessed Nov. 18, 2020).

[11] E. Monaghesh and A. Hajizadeh, "The role of telehealth during COVID-19 outbreak: a systematic review based on current evidence," BMC Public Health, vol. 20, no. 1, p. 1193, Dec. 2020, doi: 10.1186/s12889-020-09301-4.

[12] K. E. Olson, M. A. O’Brien, W. A. Rogers, and N. Charness, "Diffusion of technology: frequency of use for younger and older adults," Ageing International, vol. 36, no. 1, pp. 123-145, Mar. 2011, doi: 10.1007/s12126-010-9077-9.

[13] M. V Volkom, J. C. Stapley, and V. Amaturo, "Revisiting the digital divide: Generational differences in technology use in everyday life," N. Am. J. Psychol, vol. 16, no. 3, 2014.

[14] E. M. Agree, A. C. King, C. M. Castro, A. Wiley, and D. L. Borzekowski, “'It's got to be on this page': age and cognitive style in a study of online health information seeking," Journal of Medical Internet Research, vol. 17, no. 3, p. e79, Mar. 2015, doi: 10.2196/jmir.3352.

[15] S. Kuhn and F. Jungmann, "Medizin im digitalen Zeitalter," Der Radiologe, vol. 58, no. 3, pp. 236-240, Mar. 2018, doi: 10.1007/s00117-017-0351-7.

[16] S. Yaghobian, R. Ohannessian, A. Mathieu-Fritz, and T. Moulin, "National survey of telemedicine education and training in medical schools in France," Journal of Telemedicine and Telecare, vol. 26, no. 5, pp. 303-308, 2020.

[17] A. C. Smith et al., "Telehealth for global emergencies: Implications for coronavirus disease 2019 (COVID-19)," Journal of Telemedicine and Telecare, vol. 26, no. 5, pp. 309-313, Jun. 2020, doi: 10.1177/1357633X20916567.

[18] J. E. Hollander and B. G. Carr, "Virtually perfect? telemedicine for COVID-19," New England Journal of Medicine, vol. 382, no. 18, pp. 1679-1681, Apr. 2020, doi: 10.1056/NEJMp2003539.

[19] B. Calton, N. Abedini, and M. Fratkin, "Telemedicine in the time of coronavirus," Journal of Pain and Symptom Management, vol. 60, no. 1, pp. e12-e14, Jul. 2020, doi: 10.1016/j.jpainsymman.2020.03.019. 
[20] C. M. Contreras, G. A. Metzger, J. D. Beane, P. H. Dedhia, A. Ejaz, and T. M. Pawlik, "Telemedicine: patient-provider clinical engagement during the COVID-19 pandemic and beyond," Journal of Gastrointestinal Surgery, vol. 24, no. 7, pp. 1692-1697, Jul. 2020, doi: 10.1007/s11605-020-04623-5.

[21] G. S. Grewal and P. R. Rodríguez, "Telehealth services during the COVID-19 pandemic," 2020. https://www.njconsumeraffairs.gov/COVID19/Documents/FAQ-Telehealth.pdf (accessed Nov. 20, 2020).

[22] H. Y. Park et al., "Evaluation of a telehealth counseling program for expatriates," Telemedicine and e-Health, vol. 25, no. 8, pp. 693-700, Aug. 2019, doi: 10.1089/tmj.2018.0082.

[23] M. A. A. Imron, "Utilization of telemedicine for medical staff as a impact of the industrial revolution 4," International Conference Health, Science And Technology (ICOHETECH), vol. 98-100, 2019.

[24] C. Scott Kruse, P. Karem, K. Shifflett, L. Vegi, K. Ravi, and M. Brooks, "Evaluating barriers to adopting telemedicine worldwide: A systematic review," Journal of Telemedicine and Telecare, vol. 24, no. 1, pp. 4-12, Jan. 2018, doi: $10.1177 / 1357633 X 16674087$.

[25] Hikmahwati and W. Sulistiadi, "A systematic review: challenges and evaluations related to telemedicine as a healthcare's hope to tackle COVID-19," in Proceedings of the International Conference of Health Development. COVID-19 and the Role of Healthcare Workers in the Industrial Era (ICHD 2020), 2020, pp. 194-201, doi: 10.2991/ahsr.k.201125.033.

[26] G. Fagherazzi, C. Goetzinger, M. A. Rashid, G. A. Aguayo, and L. Huiart, "Digital health strategies to fight COVID-19 worldwide: challenges, recommendations, and a call for papers," Journal of Medical Internet Research, vol. 22, no. 6, p. e19284, 2020.

[27] A.-S. Poncette, D. L. Glauert, L. Mosch, K. Braune, F. Balzer, and D. A. Back, "Undergraduate medical competencies in digital health and curricular module development: mixed methods study," Journal of Medical Internet Research, vol. 22, no. 10, p. e22161, Oct. 2020, doi: 10.2196/22161.

[28] J. Ross, F. Stevenson, R. Lau, and E. Murray, "Factors that influence the implementation of e-health: a systematic review of systematic reviews (an update)," Implementation Science, vol. 11, no. 1, p. 146, Dec. 2016, doi: 10.1186/s13012-016-0510-7.

[29] T. Greenhalgh, J. Wherton, S. Shaw, and C. Morrison, "Video consultations for COVID-19," BMJ, vol. 368, p. m998, Mar. 2020, doi: 10.1136/bmj.m998.

[30] Pan American Health Organization, "Framework for the implementation of a telemedicine service," 2016. https://iris.paho.org/handle/10665.2/28414 (accessed Nov. 18, 2020).

\section{BIOGRAPHIES OF AUTHORS}

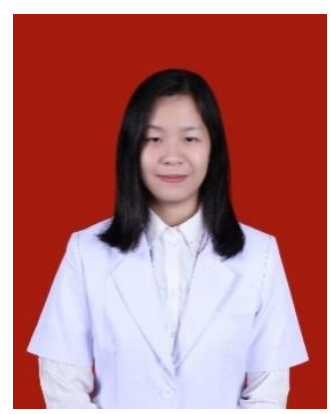

Silvalena (iD 8I SC P is a general practitioner who graduated from Sriwijaya University, Palembang, Indonesia. She is currently completing her internship at the Budhi Asih Hospital in East Jakarta. Silvalena had completed her internship program of Education and Training Department at RSIA Az-Zahra Palembang as a research assistant. She was involved in Sriwijaya University Asian Medical Student Association (AMSA) as an observer during her freshman year, later served as the Main Boards on her sophomore year. She can be contacted at email: silvasendiko@gmail.com.

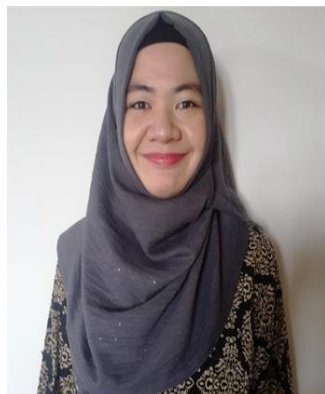

Rizma Adlia Syakurah (D) 8d SC P completed her magister degree of Hospital Administration in Universitas Indonesia and doctorate in Medical Education And Public Health in Universitas Gadjah Mada. She is currently teaching in Sriwijaya University as a lecturer. Her research interest includes health management and intervention, health promotion, health communication, medical education, and inter-professional education. She is currently also interested in management and mitigation of COVID-19 through health education and community development. She can be contacted at email: rizma.syakurah@gmail.com. 